Revista de Ciencias Sociales y Humanas de la Universidad Politécnica Salesiana

https://doi.org/10.17163/uni.n33.2020.06

\title{
Explicación del ethos discursivo de Lenín Moreno y Rafael Correa en 2018
}

\author{
Explanation of the discursive ethos \\ of Lenin Moreno and Rafael Correa in 2018
}

\author{
Byron Pacífico Andino-Veloz \\ Universidad Nacional de La Plata, Argentina \\ byronandinov@gmail.com \\ https://orcid.org/0000-0002-0455-3724
}

\begin{abstract}
Resumen
Este artículo aborda el análisis de discurso de Rafael Correa y Lenín Moreno en un nuevo contexto de Ecuador con una variación de articulaciones políticas, en el que las estrategias discursivas tienen una renovada formación del nosotros y los otros. El objetivo es indagar la construcción del ethos discursivo de ambos políticos durante 2018, a través de lo dicho por ellos sobre sí. Es un análisis cualitativo de un corpus de 16 discursos televisivos (de diferentes tipos) de Moreno y 9 de Correa. En los resultados aparece una fuerte carga de valores personales y políticos en lo manifestado por Moreno para sustentar su propuesta del diálogo y ser refundador de la institucionalidad del país, mientras que Correa enfatiza su integridad moral, se declara perseguido y se construye como un redentor de la patria para salvarla. El estudio permitió conocer cómo estas estrategias discursivas buscaron construir su imagen sobre los hechos del pasado y el presente para formarlos de manera diferencial ante sus opositores construidos.
\end{abstract}

\section{Palabras clave}

Análisis del discurso, discurso político, política, Ecuador, ethos.

\begin{abstract}
This article studies the speech analysis of Rafael Correa and Lenín Moreno in a new context of Ecuador with a variation of political articulations, in which discursive strategies have a renewed formation of us and others. The objective is to investigate the construction of the discursive ethos of both politicians in 2018 , through what they have said about themselves. It is a qualitative analysis of a corpus of 16 television speeches (of different types) by Moreno and 9 by Correa. The results show a strong possession of personal and political values of Moreno to support his proposal for dialogue and be a refounder of the country's institutionality, while Correa emphasizes his moral integrity, he declares himself persecuted and as a redeemer of the country. The study makes visible how these discursive strategies built their image about the facts of the past and the present to form it differentially before their constructed opponents.
\end{abstract}

\section{Keywords}

Speech analysis, political speech, politics, Ecuador, ethos.

Forma sugerida de citar: Andino-Veloz, B.P (2020). Explicación del ethos discursivo de Lenín Moreno y Rafael Correa en 2018. Universitas, 33, pp. 127-144. 


\section{Introducción}

Ecuador vivió un conflicto entre quienes antes eran aliados políticos: Rafael Correa y Lenín Moreno, los cuales incluso compartieron binomio como mandatario y vicepresidente desde 2007 hasta 2013 en el inicio de Alianza PAIS como gobierno. Las tensiones se produjeron cuando Moreno estaba ya en el mandato (Labarthe \& Saint-Upéry, 2017), ahí decidió apartar de puestos de poder a quienes fueron sus correligionarios para - en cambio - ubicar a nuevos agentes políticos que representaban a grupos de poder. El enfrentamiento fue por un "descubrimiento" del régimen de Moreno de que había múltiples casos de corrupción - como palabra clave para señalar al anterior gobierno de Correa (Ganuza, 2019) - así como una difícil situación económica, deuda y afectaciones heredadas para el país (Celi, 2017).

Moreno promovió nuevas articulaciones de poder y el campo político se modificó, Rafael Correa y su grupo cercano se convirtieron en sus opositores. Moreno aprovechó esta situación para conformar su estrategia discursiva con ese adversario político, a quien fustiga para legitimar su mandato. Correa, en cambio, tiene que asumir el nuevo panorama y el dominio de ese mismo contexto (el cual está a favor de Moreno) para también figurarse estratégicamente ante la mirada del otro. Dentro de esas estrategias está la construcción de su ethos: cómo se configuran Moreno y Correa en su imagen ante la gente para esta batalla política.

Tomamos como base la concepción del ethos que hace Dominique Maingueneau, ya que lo considera más allá del mismo acto de elocución, pues se trata de una noción sociodiscursiva que se integra en una situación de comunicación y en un contexto sociohistórico determinado.

Localizamos nuestro estudio $^{1}$ en el año 2018, cuando ya había una clara ruptura entre ambos políticos, nos basamos en sus discursos de diferente tipo, como cadenas y entrevistas en medios, en los que se puso mayor énfasis en lo que cada uno decía sobre sí o intentaba mostrar sobre sí. El objetivo es analizar el ethos discursivo que ambos políticos construyeron para legitimarse en la pugna interdiscursiva que mantenían, también identificamos cómo incluyen en el relato sus valores personales y políticos.

1 La información incluida en este artículo es parte de la tesis del autor, perteneciente al Doctorado en Comunicación de la Universidad Nacional de La Plata (Argentina). 
Este artículo es un aporte para el análisis del discurso político en Ecuador en este nuevo contexto, el cual incluye la formación de competidores ideológicos y adversarios (Van Dijk, 1999b), como una lucha entre enunciadores con una dimensión polémica del discurso (Verón, 1987). Las categorías de Eliseo Verón y Teun Van Dijk, como control de contexto y destinatarios, serán centrales para nuestra indagación, así como tomamos en cuenta conceptualizaciones de Ervin Goffman para comprender que el discurso se entrelaza con lo cotidiano y la cultura popular.

En este texto desentrañamos los ejes discursivos de ambos políticos que tendrán relación con la idiosincracia ecuatoriana, temas que son discutidos y puestos en relación para investigar cuáles serían sus intenciones en el campo político.

\section{Material y métodos: el ethos como práctica sociodiscursiva}

Utilizamos una metodología cualitativa para el análisis de la información del presente artículo, cuyo objetivo es el análisis del discurso de la construcción del ethos de Rafael Correa y Lenín Moreno durante 2018. El ethos ha sido discutido desde la antigua retórica, Aristóteles lo vinculaba con el carácter moral del orador, consideraba lo persuasivo para convencer a ese auditorio y ganar su confianza (Maingueneau, 2002). Sería técnica para aumentar las adhesiones de los sujetos y su consentimiento, el ethos se construiría con base en los valores y creencias que poseería el auditorio al que se dirige (Bermúdez, 2007). Es así que el ethos toma existencia en una formación discursiva.

Maingueneau (2002) aclara que el ethos se conforma por elementos prediscursivos, por la parte discursiva y por fragmentos de la propia enunciación (directa o indirecta) del enunciador, es decir, tiene una visión socio-discursiva. Con el ethos aparece el "garante", quien en los sentidos del destinatario es una representación del enunciador, tendría un "carácter" y "corporalidad" con "tono" y una "voz" (Maingueneau, 2009) y es fuente legitimadora de lo que es dicho. Es parte de la construcción de identidad y se lo identifica mediante representaciones sociales que lo evalúan positiva o negativamente, asegura el autor.

En este artículo más se explorará el ethos discursivo: el cómo Lenín Moreno y Rafael Correa hablan de sí en 2018 en el ámbito personal y político. 
Habrá dos tipos de construcción del ethos: el de Lenín Moreno será sobre su rol como mandatario que posee el control del contexto (Van Dijk, 1999a), mientras que el de Rafael Correa será de un expresidente y opositor de Moreno. Son roles en su situación de cotidianeidad política, cuya aplicación dependerá de su integración en el entorno social (Goffman, 1993).

En el corpus discursivo analizamos la construcción de los destinatarios, como indica Eliseo Verón el acto de enunciación política implica una respuesta opuesta, con un otro negativo (contradestinatario), además que se forma a un nosotros positivo (prodestinatario). Ambos son forjados mediante categorías como colectivos de identificación, entidades más amplias y metacolectivos singulares, las cuales utilizamos para indicar las relaciones entre enunciador y el destinatario.

Aclaramos que aquí indagamos la dimensión verbal, no la dimensión no verbal, por lo que buscamos la deixis personal y el nosotros inclusivo, además de los términos valorativos (Kerbrat-Orecchionni, 1997) como elementos para captar cómo se ha construido el ethos. Trabajamos con un corpus de apoyo que corresponde a los discursos de ambos políticos durante 2018, año en que hay una clara disputa interdiscursiva (Maingueneau \& Plantin, 2005) entre ellos. Cada discurso del corpus fue elegido por contener elementos relacionados a las categorías de nuestro marco metodológico:

- Lenín Moreno: 16 discursos televisivos obtenidos - en su mayoría - de la página oficial de Youtube de la Presidencia. Son transmisiones de promoción e información como El Gobierno de todos, El Presidente informa, cadenas, mensajes del Presidente, declaraciones públicas; además de entrevistas y diálogos con medios nacionales y extranjeros. Sus contenidos no son específicamente dirigidos a sus partidarios, sino a un público general mediante el poder discursivo de la comunicación gubernamental y su acceso a los medios privados, a los incautados y públicos.

- Rafael Correa: 9 discursos de entrevistas en medios nacionales, de Telesur y CNN, así como de dos discursos transmitidos en su Enlace Digital, estos últimos dirigidos a sus correligionarios tras salir del poder y realizados únicamente por internet, luego de que durante sus 10 años de gobierno el Enlace Ciudadano fuera pilar en su estrategia comunicativa al ser transmitidos en televisión y radio. A pesar de la desigualdad en el número de discursos y de la limitación 
de Correa para acceder a los medios ecuatorianos de alcance nacional (por su confrontación con el sector mediático privado), la gran cantidad de contenido y elementos de sus elocuciones permitieron desarrollar el análisis.

\section{La religiosidad y los valores presentes en el ethos}

\section{Lenín Moreno: santidad, diálogo y consenso}

Mediante el análisis se identificó las características del ethos que el Presidente Moreno quiso construir sobre sí en su relación con el poder, su forma de gobierno mediante el diálogo y sus valores en el mandato.

La exaltación de los valores y una "canonización popular"

Rosaria Minervini (2017) analizó el discurso de Lenín Moreno desde lo lingüístico y el contenido. Expresa que Moreno intenta transmitir una imagen positiva de sí, es decir, el ethos, para lo que se dibuja como una persona de confianza y fidedigna, pero con una escasez de elementos conceptuales. Entre los valores considerados positivos con los que Moreno intenta persuadir, Minervini resalta el apego a la familia y a Dios, núcleos de un pensamiento religioso que en Ecuador es predominante por la cantidad de adeptos al cristianismo.

La configuración de su imagen la realiza también desde la narración de sucesos del pasado, de su vicepresidencia en el gobierno que presidía Rafael Correa. Acude a la autorepresentación positiva como humanista y solidario por las campañas sociales que emprendió, además se pinta como político y revolucionario fiel:

Cuando se dio el $30 \mathrm{~S}$ (...) manifestaba mi lealtad con el presidente y manifestaba que la revolución no era únicamente de transformaciones sociales, sino una revolución de la lealtad porque acá era costumbre en el Ecuador que los vicepresidentes serruchen el piso a los presidentes. (Entrevista con Fernando Rincón de CNN en español, 18/abril/2018)

La narración sobre su yo incluye el verbo purgar, relacionado con el lenguaje religioso, por un sentimiento de culpa: una transgresión a una norma cultural o religiosa que se considera superior al mismo ser, es un pecado; el 
verbo purgar sería sufrir un castigo por esa falta o quitar algo malo de sí, es asumir su responsabilidad por ese pasado, lo cual lo justifica:

Pero es tarea de un ser humano también reconocer los errores. Y mi error no fue por acción, fue por omisión, me dediqué específicamente a mi trabajo social. No me preocupé jamás por el tema económico. Había sospechas por parte de muchos compañeros de que había actos de corrupción (...) Descuido sí, omisión sí y todavía estoy purgando aquello. (Entrevista con Fernando Rincón de CNN en español, 18/abril/2018)

Como resarcimiento o - siguiendo el discurso religioso - como exculpación, Moreno se define como alguien sincero (Informe a la Nación, 24/ mayo/2018), para continuar con la lucha anticorrupción, enfatiza que no tiene una doble faz en su accionar. Describe que su mandato tiene más humanismo, se muestra modesto ante lo que cree son los logros alcanzados por él en relación con un nosotros amplio:

Es mérito del pueblo ecuatoriano (...) Es cierto que algo tiene que ver el liderazgo, pero fundamentalmente el accionar de todos y cada uno de los ecuatorianos. (Entrevista con Eduardo Khalifé, Estéfani Espín y Janeth Hinostroza, 21/enero/2018)

Moreno no solo figura en sí algunos valores, sino que motiva a que se los transmitan entre todos como componente prescriptivo (Verón, 1987) que pertenece al "orden del deber", impulsa que los ciudadanos estén apegados a la justicia, igualdad, tolerancia, respeto ${ }^{2}$ solidaridad, paz, honestidad, transparencia y libertad. ${ }^{3}$

Ante los ataques políticos en su contra, exalta su personalidad, esquiva el enfrentamiento discursivo y evoca una imagen no vengativa:

Yo soy una persona feliz y que vivo en paz, en paz conmigo mismo porque procuro actuar de acuerdo a los principios, a los principios en los cuales yo creo. (El Gobierno de Todos, 9/julio/2018)

Más que una imagen de autoridad, Moreno se construye en el discurso en el ámbito emocional como un ser humano con valores y culpas por en-

2 El Presidente Informa, 29/enero/2018.

3 Cadena Nacional, 21/agosto/2018. 
mendar. A su lenguaje con tintes religiosos lo lleva a lo habitual de la política, da un indicio de construcción de una figura de santidad que:

Es un modelo de persona considerada de una conducta o prestigio superior que sirve de guía y/o orientación (...) que le ayuda a generar confianza en el individuo ante ciertas situaciones en las que pueda fallar o sufrir algún daño. (Aguilar-Vásquez, 2014, p. 36)

En este caso es guía para los ciudadanos desde la presidencia y busca una "canonización popular" (Carozzi, 2006) que le dé legitimidad (culto, en el lenguaje religioso) para ejecutar acciones políticas desde su posición de poder. Esto se verá también en los siguientes subtemas.

\section{Valores políticos y el rescate de la institucionalidad}

Moreno trata de construir una imagen de presidente responsable y desinteresado por el poder como su rol identitario (Doury, 2016). Moreno fue vicepresidente hasta mayo de 2013 y en diciembre de ese año fue designado al cargo de enviado especial de Naciones Unidas para temas de discapacidad y accesibilidad, por lo cual se trasladó a vivir a Ginebra-Suiza. Volvió para las elecciones de 2017:

Yo no quería ser Presidente, soy muy poco aficionado al poder, no me atrae el poder. Pero sí considero que si a un ser humano algún momento le corresponde ejercer el poder tiene que hacerlo con transparencia, con verdad, con trabajo. (Entrevista con Fernando Rincón de CNN en español, 18/ abril/2018).

El paradigma pronominal en primera persona del singular es construido reiterativamente para exaltar su postura en la primera oración, mientras que en la segunda retoma el componente prescriptivo del deber ser, es decir, ata a su yo como ejemplo de esos valores de ser humano y político.

Moreno se pinta como un Mandatario que devuelve la institucionalidad al país y promueve valores que considera democráticos para que las entidades del Estado sean las mejores de la historia:4 "Loor a quienes nos legaron la libertad. Una libertad que con bastante esfuerzo hemos rescatado, al igual

4 Informe a la Nación, 24/mayo/2018. 
que la tolerancia, el respeto, la alternabilidad". ${ }^{5}$ En sus discursos existe una reiteración en cuanto a la memoria patriótica (Minervini, 2017), ahora Moreno autovinculándose como un nuevo personaje histórico que habría devuelto la libertad, como un nuevo referente fundacional del país desea con sus actos marcar un antes y un después.

En diciembre de 2018, su gobierno redujo el subsidio a la gasolina súper, en un discurso público enfatizó que sus anhelos personales quedan en último lugar a la hora de gobernar para el metacolectivo singular el "país": "¡Cómo creen que yo voy a dejar de tomar decisiones que le convienen al país por preservar un cargo! Un cargo que es efímero, que tiene que ser transitorio". ${ }^{6}$ De esta forma, se entiende, justifica cualquier medida que implemente pues sería lo verdaderamente bueno para Ecuador, al cual considera un todo homogéneo y no un proceso hegemónico vigente (en el cual existen grupos sociales beneficiados por el ejercicio del poder).

Esta idea de ser respetuoso de las otras funciones del Estado no solo fue para atacar al otro construido (Correa), también la recalcó cuando su entonces vicepresidenta María Alejandra Vicuña fue acusada de cometer un delito años antes, aquí de igual forma diferencia el pasado de un presente que sería fundador de la independencia de la justicia: "no puedo ni debo actuar como juez (...) nos ha costado mucho trabajo volver a la institucionalidad, no perdamos el camino avanzado (...) sin interferencia ni órdenes desde el Palacio". ${ }^{7}$

\section{El diálogo y el fin de los conflictos políticos}

Lenín Moreno pretende construir una imagen positiva de sí al valorar positivamente a sus aliados y opositores (Minervini, 2017), al evadir el antagonismo y el enfrentamiento para concebir a la vida democrática como un diálogo para el consenso, como si la política fuera un terreno neutral y con soluciones que satisfacen a todos, lo cual esconde la diferencia de poder entre unos y otros, así como promueve el fin de las ideologías (Mouffe, 2003). Según Minervini, se trata de una relación 'yo-nosotros' en que se dibuja como un gobierno responsable, afirma estar atento a los problemas sociales del país y ser conciliador, a diferencia de la imagen confrontativa y de construcción de adversarios que poseía Rafael Correa (De la Torre, 2015).

5 Informe a la Nación, 24/mayo/2018.

6 Discurso posesión del Alto Mando militar, 20/diciembre/2018.

7 Mensaje del Presidente constitucional, 29/noviembre/2018. 
A partir de la campaña electoral de 2017, el diálogo como sustantivo es uno de los elementos que más ha resaltado y ha sido una constante en el discurso de Moreno. El diálogo es una entidad aglutinadora de varios sujetos heterogéneos seleccionados, los cuales - tras juegos de niveles de poder - producen postulados con acciones y verbos en relación con la política. Esto dota de significado al manejo del poder, sería base y justificación para la toma de decisiones.

El diálogo iría de la mano con la reconciliación. El Presidente mencionó que el régimen de Correa se peleó con todos los grupos sociales e incluso dejó familias rotas por un "fanatismo ideológico", ${ }^{8}$ pero él aclara que no tiene ese temperamento y motiva lo contrario: la reconciliación como salida del enfrentamiento y como primer paso previo al consenso, "estrechando la mano inclusive del que piensa distinto, hacerse de a buenas con el padre, con la madre, con el hermano, con el amigo, con el compañero de trabajo con el cual me distancié por temas políticos".

Segundo, abre la posibilidad de escuchar las opiniones que concuerden con principios que el gobierno manifieste. Tercero, la escucha se convierte en verbo como mecanismo para alcanzar - como deber deontológico - un consenso responsable entre varios grupos sociales y el gobierno para ver al país como un todo unitario:

Las personas que únicamente piensan en el todo o nada no están pensando en el país, hay que pensar en la necesidad de ceder espacios y consensuar, de llegar a acuerdos mínimos con el fin de salir adelante todos. (Entrevista con Eduardo Khalifé, Estéfani Espín y Jeaneth Hinostroza, 21/enero/2018).

Acudamos a un ejemplo sobre la Consulta popular. Moreno pidió (puntos 1 y 2) que la ciudadanía proponga las preguntas para ese proceso: "Gracias por darme su opinión franca, sincera, libre y patriótica. Esa opinión la necesito, la necesito para poder gobernar bien, para que este siga haciendo más que nunca el gobierno de todos". ${ }^{10}$ Así, Moreno indica que se construye con base en ese yo-nosotros, sin ese nosotros no logra constituirse en lo político. Supuestamente impulsaría una forma dialógica de intercambio de sentidos sobre las propuestas políticas para conformar las acciones gubernamentales.

8 Cadena Nacional, 21/agosto/2018.

9 Diálogo con los medios en Manabí, 19/enero/2018.

10 Declaraciones ante resultados de Consulta popular, $07 /$ febrero/2018. 
Al final, el Presidente y el gobierno decidieron (punto 3) cuáles serían las siete preguntas y la mayoría de la ciudadanía votó a favor de todas ellas: "Mi estilo no es imponer ni ordenar por caprichos, ustedes pidieron la consulta, saben bien el país que quieren y yo respeto profundamente su voluntad". ${ }^{11}$ Las preguntas elaboradas y sobre todo sus consecuencias jurídicas, políticas y sociales son justificadas por ese diálogo que habría escuchado y recogido las propuestas, así como por los valores construidos en el discurso de Moreno sobre su accionar como guía en la política. El diálogo ocupa un lugar metafórico (Verón, 1987, p. 19) sobre el conjunto de la doctrina del gobierno de Moreno con el fin de legitimar sus medidas.

Estos procesos de reconciliación-escucha-acción también aparecieron en la implementación de la Ley para la Reactivación de la Economía y para anunciar otras medidas económicas (ya con el equipo de gobierno vinculado al sector empresarial, de derecha y afines), según explicó Moreno, como producto de la conciliación ya que ese proceso había pedido el saneamiento de la economía. Aquí, el régimen anunciaba recortes, el aumento del costo de la gasolina súper y la concesión de empresas públicas.

\section{Rafael Correa: redención y antagonismo}

En el contexto de 2018, ya fuera del mandato presidencial y geográficamente lejos de Ecuador ya que residía en Bélgica (país natal de su esposa), Rafael Correa aplica un discurso para relegitimarse ya que está bajo ataque discursivo. En su ethos exalta sus valores como una honestidad incorruptible, se construye como perseguido y a la vez como redentor de la patria que está en peligro.

En nombre del pueblo y sin interés por el poder

Correa en su trayectoria construyó un ethos personal que implica una fuerza de carácter (Cerbino et al., 2016) y analogías de sí con el personaje histórico Eloy Alfaro (Ávila-Nieto, 2012), además que hace referencia a la dignidad y soberanía nacional.

Construye su yo y su nosotros con base en la diferencia:

11 El Presidente Informa, 29/enero/2018. 
Nunca nos debimos a ningún grupo de poder (...). Porque éramos gente de clase media, profesionales independientes, no somos banqueros, no somos grandes empresarios, no pertenecemos a ninguno de estos clubes exclusivos, siempre gobernamos para el bien común. (Enlace Digital \#6, 27/octubre/2018)

Los otros son enumerados y clasificados en distintas agrupaciones de poder con las cuales no se identificaría, además que cobra mayor cercanía con la gente al incluirse en esos colectivos de identificación (clase media, profesionales independientes) y alejarse discursiva y antagónicamente de otros (banqueros, empresarios).

Su ethos de virtud (Cerbino et al., 2016) poseía imágenes de sinceridad, honestidad incuestionable y fidelidad. A esto, sumamos que se proyecta como "gente sana" (no contaminada de antivalores) y afirma que ha actuado con la verdad, la razón y rectitud: ${ }^{12}$ "siempre hemos sido humanistas, hemos estado dispuestos a dar la vida por los derechos humanos, que hemos dado tantos derechos, oportunidades, justicia social". ${ }^{13}$ Aparece la imagen de redención, esto se enlaza con la siguiente declaración en la que se refiere a su "tarea histórica", habla de ese fortuito hecho de ser presidente, aunque el poder no era su interés:

Yo cumplí con mi tarea histórica, cumplí con mi parte, yo me iba a retirar de la política (...) ya alcancé todo lo que se podía alcanzar, nunca busqué nada para mí, pero la vida me premió, mi pueblo me premió con la máxima autoridad que puede operar un ciudadano que es ser Presidente de la República en 3 elecciones seguidas ganadas. Tres y yo ya no tengo nada que aspirar y jamás aspiré, solamente servir a mi patria. (Entrevista en Telesur, 4/febrero/2018)

Incluye la forma nominal "vida" como designio para ser escogido como presidente por el metacolectivo pueblo, el cual durante su mandato le habría delegado su representación para hablar en su nombre (Freidenberg, 2011). Reitera sus valores de servicio y vocación hacia otro metacolectivo: la patria.

\section{La batalla moral: integridad y honestidad incorruptibles}

"Los corruptos" es una forma nominalizada usada frecuentemente por Lenín Moreno en relación al gobierno anterior de Rafael Correa. En este

12 Enlace Digital \#6, 27/octubre/2018.

13 Entrevista en HispanTV, julio/2018. 
sentido, Correa activó como interdiscurso y necesidad deontológica un ethos sobre su yo y su nosotros para contrarrestar los ataques: "Si hay una batalla que no puede perder un revolucionario es la batalla moral, nuestra integridad es imperdonable y saben que están mintiendo". ${ }^{14}$ Primero, se construye como revolucionario para ratificar que posee una tendencia ideológica de izquierda; lo segundo es la batalla moral, en el cual un bando será el nosotros revolucionario cargado de valores e integridad, mientras que el otro es uno que miente:

Fuimos un gobierno honesto. No es que no se tiene casos de corrupción, España tenía casos de corrupción, Alemania, Estados Unidos. El que no tolera esa corrupción y la combate y eso es lo que no hemos hecho los 10 años de gobierno, en mi caso personal toda la vida, arriesgando hasta la vida por el luchar contra corrupción más aún cuando fui Presidente. (Entrevista en Palabra Suelta, EcuadorTV, enero/2018)

En este párrafo se reitera ese discurso redentor, de dar su vida por su misión. En la siguiente cita se incluye otro de los elementos reiterados en varios discursos del mandatario, en cuanto a su honestidad y muestra de integridad:

Lo único que tengo que dejar a mis hijos es mi reputación, integridad y créeme que me acusen de arbitrario, autoritario lo que ustedes quieran, pero jamás deshonesto. Pero si logran demostrar que yo tomé 20 centavos (...). Yo pude salir millonario legalmente porque recibí más de 2 millones en regalos y no había reglamentación y todo quedó para el pueblo ecuatoriano o se subastó para ayudar a los más pobres, si demuestran que me tomé 20 centavos que no son míos habría traicionado a mi patria, a mi Dios, a mi pueblo, a mi familia, a mi gente, a mi conciencia. (Entrevista en Palabra Suelta, EcuadorTV, enero/2018)

"20 centavos" se repite varias ocasiones solo en esta cita, sería una frase reiterativa de fácil recordación y entendimiento. En este caso es un elemento monetario de lo cotidiano que sustituye la idea de corrupción para negarla. En otro punto, reitera sus valores de trabajar por el "bien común" y su integridad, que su objetivo no es el dinero, sino el servicio para el metacolectivo pueblo ecuatoriano como prodestinatario. Para cerrar este apartado, nombra metacolectivos y entidades que habrían construido su identidad en

14 Entrevista en Palabra Suelta, EcuadorTV, enero/2018. 
el ethos y que lo atan a un nosotros de esa batalla moral: familia, gente, la patria, pueblo y Dios.

\section{Un ethos como víctima de persecución}

Correa construyó esta imagen al nombrar casos judiciales, decisiones electorales y políticas que iban directamente contra él y contra quienes fueron partícipes de su gobierno. El primer caso fue sobre la Consulta Popular, en la que una pregunta impedía que Correa vuelva a postularse para la presidencia en 2021: "Sí me indigna la doble moral, los atentados a los derechos humanos, que se perjudiquen los derechos de todo un pueblo por tratar de perjudicarme a mí", ${ }^{15}$ él forja una relación entre sí y el pueblo como afectados.

Ese relato de victimización lo ata también a un caso judicial en el que es acusado como autor de secuestro en Colombia de un político ecuatoriano de oposición, con apoyo de agentes de inteligencia: "por amor de Dios, salió una grabación que dice que se reunió varias veces conmigo, puro falso testimonio eso no resiste el menor análisis, cuando el fiscal me vincula, yo no soy prófugo de la justicia, soy prófugo de la injusticia”, ${ }^{16}$ así efectúa una negación polémica, no niega que jurídicamente haya sido declarado prófugo en el proceso, se apropia del término con el que lo señalan y trata de deslegitimar discursivamente a la decisión judicial.

Veamos otro fragmento similar: "Como no nos pueden vencer en las urnas, como soy el único opositor a este gobierno, todo el mundo - el resto de líderes traicioneros políticos cayeron en una complicidad - quiere destrozarnos compañeros", ${ }^{17}$ además del ethos mencionado, Correa construye como su contradestinatario directo al régimen de Moreno y a los políticos, como responsables de su persecución.

Su ethos viene cargado también de energía, fuerza y potencial por lo que acude al lugar de la ironía sobre los enunciados de sus opositores y los ubica a ellos y sus frases en el lugar del ridículo (Cerbino et al., 2016, p. 101). Por ejemplo: "Entonces como se le derrumbó todo, solo faltó que me acusen del asesinato de Atahualpa, del hundimiento del Titanic", ${ }^{18}$ así lleva a las acusa-

15 Entrevista en Canal 1, enero/2018.

16 Entrevista en Palabra Suelta, EcuadorTV, enero/2018.

17 Entrevista en Palabra Suelta, EcuadorTV, enero/2018.

18 Enlace Digital \#6, 27/octubre/2018 
ciones penales en su contra a una ironía de hechos conocidos en la historia andina y (también mediante la famosa película Titanic) acude a la memoria colectiva y los significados que puedan manejar los ciudadanos.

En los últimos meses de 2018 se desarrollaron varios procesos en su contra, negaron la inscripción de su movimiento político, entre otros hechos que afectan al grupo que apoya a Correa, por lo que como despedida de su Enlace Digital el exmandatario dijo: "Nos han hecho mucho daño, está herida la revolución, pero no está herida de muerte, quisieron enterrarnos, pero no entendieron que somos semilla y floreceremos y seguiremos adelante, ¡hasta la victoria siempre, que viva la patria!", ${ }^{19}$ acude a un cierre basado fuertemente en lo emocional por el uso de este ethos de persecución al que añade metáforas de vida y muerte para la política, así como se refiere al renacimiento político de su agrupación.

\section{Defensor de la patria y ethos redentor}

El ethos redentor que forma Correa de sí contiene elementos potentes para establecer nexos con sus prodestinatarios. Así lo vimos en apartados anteriores: él indicó que daría la vida por los derechos humanos y por la lucha contra la corrupción. Es similar al discurso religioso, asume esa figura mesiánica con distintos valores inquebrantables como encargo para la salvación del pueblo.

Ya que Correa estableció su residencia en Bélgica, podría configurarse como un nuevo "gran ausente". Según Carlos de la Torre (2015) esa figura sería para el retorno del exilio como redentor que vuelve a salvar al país, para eso debe mantenerse viva su memoria, atribuir las fallas del político a otros, a gente que se aprovechó de su bondad y sinceridad: "Tratan de impedir que volvamos a nuestra patria" ${ }^{20}$ y "a nosotros nos quieren aniquilar porque quisimos cambiar el país, lo empezamos a cambiar", ${ }^{21}$ Correa habla en primera persona del plural, promoviendo un nosotros colectivo que gobernaba y al cual los otros quieren hacer daño.

La imagen de redentor es sobre el salvador bíblico y el profeta, portador del mensaje y proveedor de felicidad y bienestar (Cerbino et al., 2016): "por defender la Revolución Ciudadana, por defender la patria nueva, por

19 Enlace Digital \#6, 27/octubre/2018.

20 Entrevista en RT, julio/2018.

21 Enlace Digital \#6, 27/octubre/2018. 
esa gente valió toda la pena, por esa gente hay que seguir creyendo", ${ }^{22}$ es defensor de la refundación de esa patria, de su metacolectivo y evoca a la fe en ese profeta que puede retornar.

"Es contra nosotros porque nosotros desafiamos al sistema porque le dimos educación a los pobres, salud, porque atendimos a las grandes mayorías, hicimos pagar impuesto a los ricos por eso nos la tienen jurada"23 aquí enlaza su discurso de autorepresentación positiva a los colectivos de identificación "pobres" y "grandes mayorías", así como construye su contradestinatario, su otro político marcado de forma antagónica: "los ricos".

Estas ideas se completarán con el componente prescriptivo de que hay que defender y luego recuperar la patria: "esto se trata de ser ecuatorianos, defender la patria porque se nos van a llevar la patria en peso, los Bucaram, los Nebot, los banqueros, los traidores y todos los que están participando en la argolla del poder", ${ }^{24}$ entonces su colectivo de identificación se convierte en una entidad más amplia como ecuatorianos ya que busca que se adhieran más ciudadanos, los paradestinatarios, ubicados como los indecisos (Verón, 1987).

Esta secuencia discursiva de Correa va así: no lo dejan volver a la patria, los quieren destrozar porque están a favor de los pobres y contra los ricos, por eso se debe defender a la patria y recuperarla. En el siguiente párrafo se puede encontrar estos elementos:

Vamos a participar así que a esperar a que no se disperse, nos espere nuestra gente, a buscar candidatos para ganar la elección del 2019, ir a una asamblea constituyente y recuperar la patria (...) este es el número de nuestros migrantes, este es el número del movimiento de nuestra Revolución Ciudadana que devolvió la patria, resucitó a la patria de las cenizas en que lo habían dejado los banqueros. (Enlace Digital \#6, 27/octubre/2018).

Primero se mantiene el metacolectivo Revolución Ciudadana, luego pide que los prodestinatarios de ese colectivo esperen su retorno para defender y recuperar la patria mediante la constituyente, la redención se ratifica al recordar que ellos son quienes ya salvaron y resucitaron antes a la patria tras el feriado bancario de 1999 y pueden hacerlo de nuevo, por lo que acude a la memoria colectiva. Este constante uso del lenguaje religioso se empata con la

22 Entrevista en HispanTV, julio/2018.

23 Enlace Digital \#6, 27/octubre/2018.

24 Entrevista en Palabra Suelta, EcuadorTV, enero/2018. 
religiosidad popular: la esperanza de los creyentes de que el orden sea subvertido por Dios como justicia, como una revancha de los pobres (Carozzi, 2006).

\section{Discusión y conclusiones}

La construcción del ethos discursivo permite visibilizar elementos de la estrategia de los políticos, los cuales se proyectan hacia los demás para ponerse en relación con los sentidos de ciudadanos y así buscar legitimidad. Se recuerda, según Maingueneau, que el ethos es una puesta en juego, es la composición entre lo mostrado, lo dicho de sí y el ethos prediscursivo, así como el ethos efectivo que se visibiliza en los sentidos de los destinatarios, lo cual por el límite de este artículo no ha podido ser más discutido.

El presente estudio es sobre un contexto que poseía enfrentamiento y una dimensión polémica (Verón, 1987) en el campo político, en el que aparecen dos visiones discursivas: la una con la lógica del consenso y la otra basada en una confrontación política. Aprovechando los recursos de poder comunicativos del gobierno y sus nexos con los medios privados, el Presidente Lenín Moreno - mediante el discurso post-político (Mouffe, 2003) que es utilizado por el neoliberalismo en lo contemporáneo- buscaba representar negativamente a su adversario para legitimar su cambio de orientación política y no respetar el programa por el que fue electo, aduciendo que no existía otra alternativa más que el diálogo. A la vez se construía a sí como imagen opuesta a Rafael Correa por sus características diferenciales.

Correa recibió ataques de los medios y de la comunicación gubernamental, lo cual él también practicaba en su mandato. En ese nuevo contexto, Correa respondió interdiscursivamente mediante su autoexaltación para no perder terreno ante la ausencia del control del contexto comunicativo, ya que estaba fuera del poder gubernamental y los medios estaban en su contra. A la vez, el giro político de Moreno le sirve a Correa para justificar que existió una "traición" al pueblo, enfatizando la lógica antagónica.

La estrategia de Moreno forjó en su ethos discursivo la limpieza de su imagen del pasado y su ratificación de honestidad y desinterés por el poder en el presente. En busca de legitimidad acude a un relato religioso, construye una especie de figura de santidad en sí con una enumeración continua de valores para que los ciudadanos se vuelvan creyentes, los repliquen y coloquen su fe en él como guía confiable. Mediante el saber que obtenga en el 
proceso de diálogo (que consistiría en la reconciliación, escucha y acción), Moreno aspiraría ser el refundador de la institucionalidad del país.

Aquí coincide que Correa y Moreno acuden a discursos con tintes religiosos, dada la matriz cultural presente en Ecuador por la presencia del cristianismo a lo largo de su historia. Correa, por su parte, se dibuja como el redentor que llegó hace unos años desde grupos ciudadanos alejados del poder, con una moral incorruptible, para salvar al país tras la difícil situación que se vivió por la inestabilidad gubernamental y afectaciones económicas y sociales. Hoy se muestra como alguien perseguido por haber actuado a favor de los más vulnerables, del pueblo, y no de los grupos de poder. Su experiencia en el mandato es su justificación y base para mantenerse en el accionar político, para buscar recuperar la patria -que significaría obtener otra vez el poder- y ser nuevamente el salvador del país.

El conocer mediante este estudio el ethos discursivo del Lenín Moreno y su principal opositor en Ecuador permite también un análisis del juego de las representaciones de los políticos que está en disputa. Es parte del proceso de lucha y constitución del poder en un proceso hegemónico, en este caso la disputa por la legitimidad política entre el nosotros y los otros construidos desde Correa y Moreno.

\section{Bibliografía}

Aguilar-Vásquez, L.E. (2014). El lenguaje religioso utilizado en los discursos políticos de los presidentes de El Salvador desde el año 1989 hasta el año 2013. (Tesis de maestría). El Salvador: Universidad Centroamericana José Simeón Cañas.

Ávila-Nieto, C. (2012). El mito como elemento estratégico de comunicación política: aplicación del modelo de Barthes al caso ecuatoriano. Cuadernos.info (31), 139-150. http://dx.doi.org/10.7764/cdi.31.447

Bermúdez, N. (2007). La noción de ethos: historia y operatividad analítica. Revista electrónica de estudios filológicos (14). https://bit.ly/2unkKuS

Carozzi, M. (2006). Antiguos difuntos y difuntos nuevos. Las canonizaciones populares en la década del 90'. En Entre santos, cumbias y piquetes: las culturas populares en la Argentina reciente (pp.91-110). Biblios.

Celi, M. (2017). Lenín Moreno: ¿un punto de inflexión para Alianza País?. Revista Nueva Sociedad (269), 4-16. https://bit.ly/384Ifr7

Cerbino, M., Maluf, M., \& Ramos, I. (2016). Los Enlaces Ciudadanos del presidente Rafael Correa: entre la exaltación del pueblo y el combate a los medios. FLACSO Ecuador. 
De la Torre, C. (2015). De Velasco a Correa. Insurrecciones, populismos y elecciones en Ecuador 1944-2013. Corporación Editora Nacional.

Doury, M. (2016). Argumentation. Analyser textes et discours. Armand Colin.

Freidenberg, F. (2011). Los nuevos liderazgos populistas y la democracia en América Latina. LASA FORUM XLII: 9-11.

Ganuza, C. (2019). Deconstrucción del orden político de Ecuador mediante el análisis crítico de los discursos de Lenin Moreno (2017-2018). Revista Scientific, 4(14), 24-43. https://doi.org/10.29394/Scientific.issn.25422987.2019.4.14.1.23-43

Goffman, E. (1993). La presentación de la persona en la vida cotidiana. Amorrortu. Kerbrat-Orecchionni, C. (1997). La enunciación. De la subjetividad en el lenguaje. Edicial.

Labarthe, S., \& Saint-Upéry, M. (2017). Leninismo versus correísmo: la «tercera vuelta» en Ecuador. Nueva Sociedad (272), 29-42. https://bit. ly/2vWRCLz

Maingueneau, D (2002). Problèmes d'ethos. Pratiques (113-114), 55-67. https://bit. ly/2S1Smr6

Maingueneau, D. (2009). Análisis de textos de comunicación. Nueva Visión.

Maingueneau, D., \& Plantin, C. (2005). Diccionario de Análisis del Discurso. Amorrortu.

Minervini, R. (2017). Análisis de un discurso político: la investidura de Lenín Moreno. Cultura Latinoamericana. Revista de Estudios Interculturales, 5473. doi: 10.14718/CulturaLatinoam.2017.26.2.3

Mouffe, C. (2003). La paradoja democrática. Gedisa.

Van Dijk, T. (1999a). El análisis crítico del discurso. Anthropos (186), 23-36. https:// bit.ly/2Ow6Sp5

Van Dijk, T. (1999b). ¿Qué es análisis de discurso político? En I. Rodrigo, y T. Van Dijk, Análisis del discurso social y político. Serie Pluriminor, Abya Yala. https://bit.ly/3gMOuo5

Verón, E. (1987). La palabra adversativa. Observaciones sobre la enunciación política. En E. Verón, El discurso político: Lenguajes y acontecimientos (pp. 1126). Hachette.

Fecha de envío: 2020/02/12; Fecha de aceptación: 2020/07/08;

Fecha de publicación: 2020/09/01 